\title{
Inteligência competitiva: revisão sistemática da produção nacional
}

\section{Anna Carolina Mendonça Lemos Ribeiro ${ }^{I}$ http://orcid.org/0000-0003-3691-8422}

Almir de Oliveira Junior ${ }^{I I}$

http://orcid.org/0000-0001-8568-6088

${ }^{I}$ Universidade de Brasília, DF, Brasil

Técnica de Desenvolvimento e Administração - Ipea.

Doutoranda do Programa de Pós-Graduação em Administração da Universidade de Brasília - PPGA/UnB.

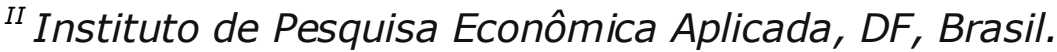

Técnico de Planejamento e Pesquisa na Assessoria de Planejamento e Articulação Institucional - Ipea. Professor Doutor do Mestrado Profissional em Políticas Públicas e Desenvolvimento - Ipea.

\section{http://dx.doi.org/10.1590/1981-5344/4187}

Neste trabalho se objetivou realizar uma revisão da produção nacional, em periódicos nacionais de primeira linha, nas áreas de administração e de ciência da informação, sobre inteligência competitiva. O estudo é de abordagem qualitativa e de natureza descritiva, adotando como procedimento a revisão sistemática da literatura. Segundo os critérios de seleção, os resultados indicam que os estudos sobre IC são:escassos; preponderantemente referentes à esfera privada; predominantemente da área da ciência da informação;não possuem uma regularidade linear de publicação; e apresentam maior pico de publicação em 2013.

Palavras-chave: inteligência competitiva; administração; ciência da informação; revisão sistemática. 


\section{Competitive intelligence: a systematic review of national production}

In this work, the objective was to carry out a review of the national production on competitive intelligence in top national journals, in the areas of administration and information science. The study is descriptive and has a qualitative approach, adopting the systematic literature review as a procedure. According to the selection criteria, the results indicate that studies on CI are scarce and preponderant to the private sphere, as well as predominant in the area of information science, do not have a linear publication regularity and have a higher publication peak in 2013.

Ke ywords: competitive intelligence; management; information science; systematic review.

Recebido em 07.11.2019 Aceito em 24.08.2021

\section{Introdução}

A inteligência é apresentada por Kent (1949) como tendo um triplo significado: é considerada como uma atividade (ou seja, processo de produção de inteligência), ao mesmo tempo que também é um produto dessa atividade (informação analisada para servir de base para a decisão) e uma unidade organizada para realizar tal atividade (formada por pessoal especializado em conduzir a atividade). O seu principal objetivo é auxiliar o processo decisório ao antecipar os movimentos de atores do macroambiente e no ambiente organizacional, evitando, assim, que a organização seja surpreendida, especialmente por atores-chave (MARCIAL, 2011).Nesse sentido, adota-se o entendimento de Ribeiro e Santos (2020), ao considerar a inteligência como a capacidade de analisar o conhecimento com 0 intuito de decidir por ações mais eficientes.

O processo de inteligência é formado por um ciclo, geralmente composto por quatro fases: 1) planejamento; 2) coleta; 3) análise; e 4) difusão (BATTAGLIA, 1999; CAPUANO et al., 2009; KAHANER, 1996). Para a realização desse processo sistemático, são requeridos procedimentos, políticas e uma infraestrutura formal ou informal apropriados, de forma a ser possível que os profissionais de inteligência possam contribuir efetivamente para o sistema de inteligência (DISHMAN;CALOF, 
2007). Esse sistema, segundo Battaglia (1999), é específico de cada organização, pois suas atividades dependem das necessidades de informação estratégica, dos recursos existentes e de seus objetivos e funções.

Pela complexidade, o escopo da atividade de inteligência não é pequeno, razão pela qual se tem aplicado adjetivos para esclarecer melhor o seu foco de atuação. A Inteligência Militar, por exemplo, que deu origem a todas as outras, cuida dos assuntos típicos da dinâmica militar. A Inteligência de Estado, restrita à esfera estatal, lida com tudo o que os órgãos governamentais oficiais de inteligência produzem (HERMAN, 1996). A Inteligência Estratégica (IE) se relaciona à gestão estratégica (GE) da organização, subsidiando as decisões de caráter estratégico (BESSON;POSSIN, 1997). E a IC, melhor especificada a seguir, lida com questões das organizações de modo a lhes orientar adequadamente para a obtenção de vantagens competitivas (FERNANDES, 2012).

A IC, fruto da Inteligência Militar aplicada aos negócios (MARCIAL, 2016), não é uma atividade nova, mas é relativamente incipiente enquanto campo de estudo (DE PELSMACKER et al., 2005; MARCIAL, 2012), diferente das demais citadas no parágrafo anterior. Surgiu como prática organizacional na década de 1950, no Japão e na Europa, e apresentou evolução mais relacionada à atuação profissional do que à pesquisa até a década de 1970 (MARCIAL;SUAIDEN, 2016). Apresenta-se na literatura com uma série de definições distintas (CAPUANO et al., 2009; SØILEN, 2015; PELLESSIER;NEZHELLE, 2013; MARCIAL, 2016), ocasionando especial confusão em relação ao seu conceito, inclusive embaralhando-se indistintamente com outras disciplinas do conhecimento (GUEDES; CÂNDIDO, 2008). Além disso, sua própria nomenclatura pode se misturar com outras adjetivações da inteligência, tal como notado por Fachinelli et al. (2013), algumas vezes definidas mais por influências geográficas e culturais do que por diferenças na estrutura conceitual.

No Brasil, Rios et al. (2011), ao realizarem uma revisão de literatura nacional para análise das características dos diferentes conceitos, identificaram termos que convergem no entendimento de que o foco da inteligência se encontra no ambiente de competição como um todo, a saber: IC, Inteligência Estratégica Antecipativa, Inteligência Empresarial e Inteligência Empresarial Estratégica. Os autores concluíram que, embora não haja um consenso sobre a nomenclatura usada, tais adjetivações da inteligência apresentam-se como conceitos vizinhos.

Visando dar uma resposta à essa discussão conceitual, Pellessier e Nezhelle (2013) sugerem uma definição universal de IC, após revisarem as variações encontradas na literatura, a saber: processo ou prática que produz e dissemina inteligência por meio de planejamento, coleta ética e legal, processamento e análise de informação do ambiente interno, externo ou competitivo, e a respeito dele, a fim de ajudar os decisores na tomada de decisão e de fornecer vantagem competitiva para a organização. A proposta dos autores apresenta características típicas da inteligência (possui um ciclo de produção de inteligência, finalidade de 
assessoramento, monitoramento de atores, ética e legalidade na coleta de dados), restando como específico para a IC o fornecimento de vantagem competitiva para a organização. Assim, a definição de IC adotada neste trabalho é: "atividade de inteligência que visa fornecer vantagem competitiva para a organização".

Por vantagem competitiva, entende-se a capacidade ou recurso que dá à organização uma vantagem sobre seus concorrentes que leva a um desempenho relativo mais alto (WIGGINS;RUEFLI, 2002). Ao analisar as capacidades, vulnerabilidades, intenções e movimentos dos concorrentes, a IC permite que uma organização antecipe proativamente os desenvolvimentos do mercado, em vez de simplesmente reagir a eles (BOSE, 2008).

Kira Tarapanoff (2006), parece corroborar com esse entendimento, ao considerar que a IC é o processo de aprendizado motivado pela competição, tendo como base a informação.Por tal razão, é de suma importância para as organizações que pretendem ser competitivas no mercado(PRADO, CAMPOS, 2018; VALENTIM et al., 2003).

Nesse contexto, os estudos relacionados à IC no Brasil focam predominantemente nas empresas privadas, restando poucos voltados a metodologias e técnicas para organizações públicas, demonstrando fragilidade da pesquisa sobre essa temática na esfera governamental e a potencial necessidade de ampliação de estudos no setor (ALMEIDA; MARICATO, 2015). Mendes, Marcial e Fernandes (2010) afirmam, todavia, que observaram um número cada vez maior de organizações públicas e privadas investindo em IC, em especial. De todo modo, Silva e Andrade (2013) apontam que muitos órgãos públicos ainda não dão importância à utilização desse processo por algumas razões, sendo umas delas o entendimento - considerado pelos autores como equivocado - de que não há concorrência.

Wagner (2003) afirma que a concorrência direta, muitas vezes, não é mesmo considerada relevante no setor público. Pouca energia da organização pública é dedicada à estratégica em busca de uma vantagem competitiva sustentável, embora, a concorrência ocorra não apenas para os clientes, mas também para financiamento e pessoal. Nesse entendimento, o autor ainda afirma que as atividades de IC podem ajudar uma organização do setor público de duas formas. A primeira, como uma função necessária para a organização pública, lidando com o aumento de serviços aos usuários finais e mensuração das expectativas dos stakeholders. A segunda, como um autosserviço e sobrevivência da organização, melhorando o serviço e a medição do desempenho em relação aos concorrentes.

Sob outra ótica, Silva e Gonçalves (2011) entendem que, em órgãos públicos, o foco não é o lucro nem a busca por vantagens competitivas, haja vista não existir concorrência na forma como é verificada na esfera 
privada. Nessa vertente, pode-se inferir que a IC não se aplicaria a organizações públicas. Assim, além da escassez de estudos sobre a IC em organizações públicas, o que se tem também é uma falta de consenso sobre a própria concepção de competitividade no setor público.

Com o intuito de melhor esclarecer a forma como os estudos sobre IC têm se apresentado na produção nacional, considerando ser este um campo ainda emergente e com certas imprecisões conceituais, este trabalho pretende realizar, com base na proposta protocolar de Cronin, Ryan e Coughlan (2008), uma revisão sistemática das publicações de primeira linha de administração e ciência da informação.

\section{Procedimentos metodológicos}

Esta pesquisa é de abordagem qualitativa e de natureza descritiva, empregando como procedimento a revisão sistemática da literatura. Para o seu cumprimento, utilizou-se o protocolo de Cronin, Ryan e Coughlan (2008), formado pelas seguintes cinco etapas.

Fase 1 - Formulação da questão de pesquisa

Este artigo busca responder a seguinte questão precípua de pesquisa: qual o panorama estabelecido das publicações nacionais sobre IC?

Fase 2 - Definição do conjunto de critérios de inclusão e exclusão

Foram selecionados os artigos da base de periódicos da Coordenação de Aperfeiçoamento de Pessoal de Nível Superior (Capes), na Base de Dados Referencial de Artigos de Periódicos de Ciência da Informação (Brapci) e na Scientific Electronic Library Online (SciELO), de acordo com os seguintes critérios de busca, realizada de 13 a17 de agosto de 2021: i) descritor "inteligência competitiva", no título, assunto ou palavras-chave; ii) tipo de material: artigos; iii) sem horizonte temporal; iv) periódicos revisados por pares.

Como critério de inclusão, estipulou-se: a) artigos publicados apenas em periódicos nacionais de primeira linha (estratos de avaliação iguais ou superiores a A1 - quadriênio 2013-2016 - no Sistema Qualis da Capes), em qualquer idioma, de modo a priorizar artigos com maior qualidade de conteúdo; b) artigos publicados em periódicos de administração e ciência da informação (CI), áreas que possuem a IC como objeto de pesquisa (BARRANCOS; DUARTE, 2013); e c) artigos que tivessem a IC como tema principal (mesmo relacionada a outros temas), não como secundário.

Fase 3 - Seleção e acesso da literatura

A recuperação dos artigos se deu por meio da busca nas três bases de dados indicadas na Fase 2, seguindo os critérios informados. Foram recuperados inicialmente 357 artigos. 
Fase 4 - Avaliação da qualidade da literatura incluída na revisão

Dos 357 artigos recuperados na busca, 312 foram excluídos pelas seguintes razões: i) publicados em periódicos internacionais; ii) duplicados; iii) sem aderência preliminar ao tema ou abordagem ao tema de forma secundária, após leitura preliminar; iv) publicados em periódicos com classificação inferior a A2 em sua área de atuação principal, recorte estipulado para que fossem analisados apenas periódicos melhor avaliados, o que infere artigos com qualidade superior; e, v) não eram artigos científicos. Ademais, foram agrupados dois artigos, publicados no mesmo periódico, no mesmo ano, com os mesmos autores, por serem partes 1 e 2 do mesmo trabalho. Assim, 45artigos compõem o estrato final deste estudo, eis que cumpriram com todos os critérios de seleção indicados.

Dos artigos selecionados, quinze estavam disponibilizados apenas na Brapci; doze nas três bases de dados; onze, na Brapci e na base da Capes; três, apenas da Capes; três, na Brapci e no SciELO; e um foi encontrado na Capes e no SciELO.

Fase 5 - Análise, síntese e disseminação dos resultados

Nesta etapa, realizou-se a avaliação detalhada dos 45artigos selecionados, apresentados na Tabela A, disposta no Apêndice, sobre os quais foi efetuada a revisão sistemática da literatura. Na seção dos resultados, os artigos serão referenciados de acordo com o número respectivo na coluna $\mathrm{N}$ da Tabela $\mathrm{A}$. $\mathrm{Na}$ análise dos artigos, foram levantados os indicadores das seguintes categorias: 1) nome do periódico; 2) classificação Qualis do periódico; 3) área principal de atuação do periódico; 4) ano de publicação; 5) quantidade de autores; 6) vinculação acadêmica dos autores; 7) assuntos relacionados à IC nos estudos; e 8) enquadramento do estudo. Ainda, para os artigos enquadrados como teórico-empíricos, também foram analisados: 9) natureza da pesquisa; 10) setor da economia; 11) ramo de atuação das organizações pesquisadas; 12) instrumentos utilizados para coleta de dados; e 13) técnicas de análise de dados empregadas.

\section{Resultados e discussão}

Esta seção visa apresentar os principais resultados do estudo, com síntese ilustrada acerca do levantamento dos 45 artigos analisados. Com base nesses resultados, pode-se traçar um cenário sobre a evolução dos estudos nacionais dedicados à IC.

\subsection{Periódico}

O Quadro 1 sumariza os periódicos, com classificação Qualis igual ou superior a A1, que publicaram artigos sobre IC, de acordo com os critérios de busca adotados. Respeitando o critério de se analisar somente os dois estratos Qualis mais elevados, seis periódicos foram recuperados, todos 
da área da CI, a saber: Perspectivas em Ciência da Informação classificação A1 (33,33\%), Encontros Bibli: Revista Eletrônica de Biblioteconomia e Ciência da Informação -A2 (24,44\%), Transinformação -A1 (20\%), Informação \& Informação - A1 (13,33\%), Informação \& Sociedade $(6,67 \%)$ e Em Questão $(2,22 \%)$.

Quadro 1 - Distribuição dos artigos de acordo com o periódico

\begin{tabular}{|l|c|c|c|c|}
\hline \multicolumn{1}{|c|}{ Periódico } & Qualis & $\begin{array}{c}\text { Area de } \\
\text { atuação }\end{array}$ & Qtde & $\%$ \\
\hline Perspectivas em Ciência da Informação & $\mathrm{A} 1$ & $\mathrm{Cl}$ & 15 & 33,33 \\
\hline Encontros Bibli & $\mathrm{A} 2$ & $\mathrm{Cl}$ & 11 & 24,44 \\
\hline Transinformação & $\mathrm{A} 1$ & $\mathrm{Cl}$ & 9 & 20 \\
\hline Informação \& Informação & $\mathrm{A} 2$ & $\mathrm{Cl}$ & 6 & 13,33 \\
\hline Informação \& Sociedade & $\mathrm{A} 1$ & $\mathrm{Cl}$ & 3 & 6,67 \\
\hline Em Questão & $\mathrm{A} 2$ & $\mathrm{Cl}$ & 1 & 2,22 \\
\hline \multicolumn{2}{|l|}{ TOTAL } & & $\mathbf{4 5}$ & $\mathbf{1 0 0}$ \\
\hline
\end{tabular}

Fonte: Elaboração própria.

A ausência de periódicos recuperados da área de administração vai de encontro com os achados de Marcial e Suaiden (2016), que apontaram que os dois principais campos do conhecimento que investigam a IC são a administração $(43,2 \%)$ e a CI (22,4\%). Como Correia et al. (2018) esclarecem que a IC é uma ferramenta eminentemente de gestão, aplicando funções típicas dos estudos da administração, como planejamento, organização, direção e controle, esses resultados parecem indicar que as publicações nessa área sobre a temática devem ocorrer em periódicos nacionais com estratos inferiores ou em periódicos internacionais.

\subsection{Ano de publicação}

O ano 2013 apresentou sete artigos, seguido de 2018, com seis, e de 2004 e 2016, com cinco artigos cada. Os anos 1999, 2005 e 2006 indicaram três publicações, enquanto 2001, 2009, 2012, 2015 e 2020, duas, e 2008, 2017 e 2021, apenas uma. Os anos 2000, 2002, 2003, 2007, 2010, 2011, 2014 e 2019 não apresentaram nenhum artigo. A Figura 1 simplifica esses resultados. 
Figura 1 - Distribuição dos artigos de acordo com o ano de publicação

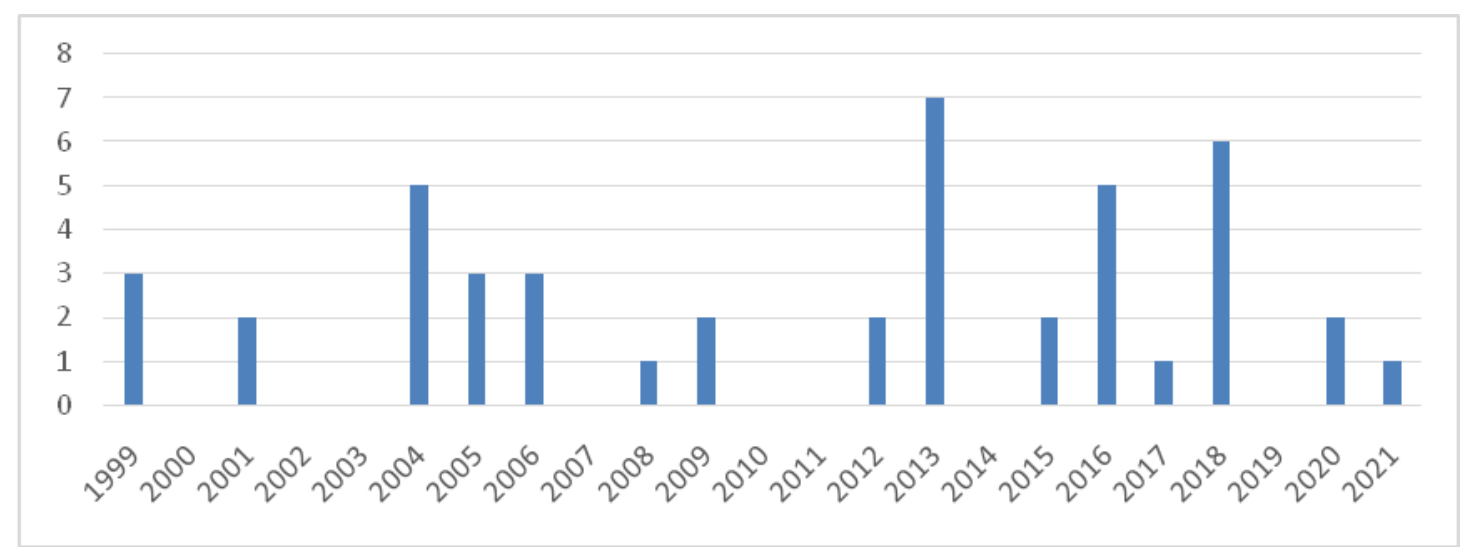

Fonte: Elaboração própria.

Em conformidade com os critérios de seleção desta pesquisa, de acordo com a Figura 1, o primeiro ano que publicou sobre IC foi 1999, sendo marcado por três artigos. No ano seguinte, não houve publicação. Somente em 2001 ocorreram mais duas, então somente em 2004, com cinco artigos. A temática da IC é relativamente recente como objeto de estudo nos periódicos nacionais especializados nas áreas e, de modo algum, apresenta um crescimento linear no número de publicações ano a ano. Por algum motivo não detectado, aparecem alguns lapsos temporais significativos na produção dos artigos a respeito da IC após 2004 (2007, entre 2010 e 2011, 2014 e 2019). Já os picos de publicações ocorreram em 2013, com sete artigos, e em 2018, com seis. Contudo, na sequência, respectivamente, em 2014 e 2019, como dito, não houveram artigos publicados.Há evidente falta de regularidade de publicações nacionais sobre o tema.

Esses resultados estão alinhados com os achados de Correia et al. (2018), no contexto internacional. Segundo os autores, que analisaram 263 artigos sobre IC em periódicos internacionais, no período de 1998 a 2017, os trabalhos indicam períodos de oscilação, apresentando produção maior nos anos de 2013 e 2016.

Ademais, considerando o horizonte temporal de 22anos de publicação (não incluindo 2021, em razão de sua incompletude), 44estudos correspondem a apenas 2 artigos por ano em média, indicando uma significativa escassez de pesquisas sobre a temática em periódicos nacionais de primeiro escalão. 


\subsection{Número de autores}

Vinte artigos foram assinados por uma dupla de pesquisadores; nove por três estudiosos ou por apenas uma pessoa; três artigos por quatro pesquisadores; e dois por cinco autores. Artigos com oito e 10 pesquisadores apareceram apenas uma vez. A Figura 2 esquematiza essa distribuição de 116autores no total.

Figura 2 - Distribuição dos artigos de acordo com o número de autores por artigo

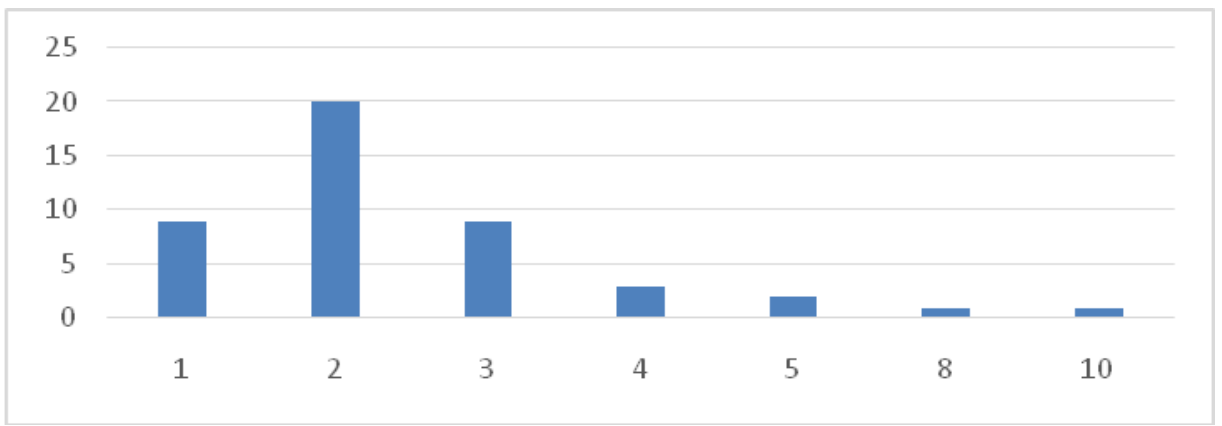

Fonte: Elaboração própria.

Em relação ao número de autores, $44,44 \%$ dos artigos foram assinados por uma dupla de pesquisadores. Sequencialmente, $20 \%$ dos estudos foram desenvolvidos por três estudiosos e $20 \%$ por apenas uma pessoa; $6,67 \%$ por quatro pesquisadores; e 4,44\% por cinco pesquisadores. Artigos com mais autores ( 8 e 10) autores despontaram apenas uma vez. Assim, a produção nacional em estratos superiores a respeito da IC tem se dado, em sua maioria, com autoria coletiva. Isso pode indicar que, em alguma medida, os estudos sobre IC têm envolvido pesquisa em equipe, em contraposição ao trabalho individual.

\subsection{Vinculação acadêmica}

O Quadro 2 exibe a vinculação acadêmica dos 116 autores dos artigos selecionados, vinculados a 34instituições distintas. As mais mencionadas são: 1) Universidade Estadual de Londrina (UEL), com 17 autores, em quatro artigos distintos; 2) Universidade Federal de Minas Gerais (UFMG), com 15pesquisadores, em nove publicações; 3) Universidade de Brasília (UnB), com nove pesquisadores, em cinco artigos distintos; 4) Universidade Federal de São Carlos (UFSCar), com oito autores, em três publicações; e 5) Universidade Estadual Paulista (Unesp) e Universidade Federal de Santa Catarina (UFSC), com sete pesquisadores, em três artigos cada. As demais instituições foram representadas por um a cinco autores, em um a quatro artigos.

Percebe-se, portanto, que mais da metade $(54,31 \%)$ dos autores envolvidos estavam ligados a apenas seis universidades: UEL, UFMG, UnB, 
UFSCar, Unesp e UFSC. Embora a UEL tenha sido a instituição que apresentou o maior quantitativo de autores, sua participação ocorreu em apenas quatro artigos. A UFMG foi a que participou de maior quantidade de artigos distintos.

Quadro 2 - Distribuição da vinculação acadêmica

\begin{tabular}{|l|c|c|}
\hline \multicolumn{1}{|c|}{ Vinculação acadêmica } & $\begin{array}{c}\text { Qtde } \\
\text { Autores }\end{array}$ & $\begin{array}{c}\text { Qtde } \\
\text { Artigos }\end{array}$ \\
\hline Universidade Estadual de Londrina (UEL) & 17 & 4 \\
\hline Universidade Federal de Minas Gerais (UFMG) & 15 & 9 \\
\hline Universidade de Brasília (UnB) & 9 & 5 \\
\hline Universidade Federal de São Carlos (UFSCar) & 8 & 3 \\
\hline Universidade Estadual Paulista (Unesp) & 7 & 3 \\
\hline Universidade Federal de Santa Catarina (UFSC) & 7 & 3 \\
\hline Pontifícia Universidade Católica de Campinas (PUC Campinas) & 5 & 4 \\
\hline Universidade Federal da Paraíba & 4 & 2 \\
\hline Instituto Federal de Minas Gerais (IFMG) & 4 & 2 \\
\hline Universidade Federal do Rio de Janeiro (UFRJ) & 4 & 2 \\
\hline Centro de Pesquisa e Desenvolvimento em Telecomunicações (CPqD) & 3 & 2 \\
\hline Universidade Católica de Brasília (UCB) & 3 & 1 \\
\hline Universidade Fumec & 3 & 2 \\
\hline Centro Federal de Educação Tecnológica Celso Suckow da Fonseca & 2 & 2 \\
\hline (CEFET/RJ) & 2 & 1 \\
\hline Fundação Pedro Leopoldo & 2 & 1 \\
\hline lbmec Business School & 2 & 2 \\
\hline Pontifícia Universidade Católica de Minas Gerais (PUC Minas) & 2 & 1 \\
\hline Universidade de São Paulo (USP) & 2 & 2 \\
\hline Aix Marseille Université & 1 & 1 \\
\hline Associação do Desenvolvimento Tecnológico de Londrina & 1 & 1 \\
\hline Colégio Pontual & 1 & 1 \\
\hline Faculdades Claretianas & 1 & 1 \\
\hline Fundação Getulio Vargas (FGV) & 1 & 1 \\
\hline Instituto Brasileiro de Informação em Ciência e Tecnologia (IBICT) & 1 & 1 \\
\hline Instituto Cultural Brasil-Estados Unidos & 1 & 1 \\
\hline Instituto Federal de Educação, Ciência e Tecnologia da Paraíba (IFPB) & 1 & 1 \\
\hline Petrobras & 1 & 1 \\
\hline Sociedade Técnica Educacional de Minas Gerais (COTEMIG) & 1 & 1 \\
\hline Universidade Católica de Goiás & 1 & 1 \\
\hline Universidade de Lisboa & 1 & 1 \\
\hline Universidade Estadual da Paraíba & 1 & 1 \\
\hline Universidade Federal de Goiás (UFG) & 1 & 1 \\
\hline Universidade Federal do Norte Fluminense & 1 & 1 \\
\hline Universidade Metodista de Piracicaba (UNIMEP) & 1 & 1 \\
\hline Não informado & 1 & 1 \\
\hline Fonte: Eaboraça própia. & & \\
\hline
\end{tabular}

Fonte: Elaboração própria.

\subsection{Assuntos relacionados à IC}


Dezenove versaram apenas sobre a IC. Os demais (26) relacionaram tal temática a outros assuntos, conforme ilustra o Quadro 3. A gestão do conhecimento foi o assunto mais discutido nos artigos, conjuntamente com a IC, com sete artigos, seguido de fontes informacionais, inovação e redes sociais, em dois estudos cada. Os demais temas foram tratados apenas em uma publicação.

Assim, nos casos em que a IC é discutida em associação com outros tópicos, a gestão do conhecimento é o assunto dominante. Esse resultado corrobora com Capuano et al. (2009), que verificaram que a IC já vinha se beneficiando do aumento da gestão do conhecimento a uma função mais destacada nas organizações. De todo modo, os resultados confirmam o caráter interdisciplinar da IC, que se articula com uma infinidade de temas, inclusive de outras áreas do conhecimento, como ciência da informação, administração, ciência da computação, economia e psicologia (CORREIA et al., 2019).

Quadro 3 - Distribuição dos assuntos correlacionados à IC

\begin{tabular}{|l|c|}
\hline \multicolumn{1}{|c|}{ Assuntos } & Qtde \\
\hline Gestão do conhecimento & 7 \\
\hline Fontes informacionais & 2 \\
\hline Inovação & 2 \\
\hline Redes sociais & 2 \\
\hline Big data & 1 \\
\hline Cenários prospectivos & 1 \\
\hline Ciência da informação & 1 \\
\hline Compartilhamento de informações & 1 \\
\hline Comportamento informacional & 1 \\
\hline Conhecimento organizacional & 1 \\
\hline Desenvolvimento sustentável & 1 \\
\hline Ensino & 1 \\
\hline Fluxos de informação & 1 \\
\hline Gestão da informação & 1 \\
\hline Inteligência de negócios & 1 \\
\hline Internet & 1 \\
\hline Marketing & 1 \\
\hline Mídias sociais & 1 \\
\hline Monitoramento informacional & 1 \\
\hline Propriedade industrial & 1 \\
\hline Telecomunicação & 1 \\
\hline Profissional da informação & 1 \\
\hline Planejamento estratégico & 1 \\
\hline
\end{tabular}

Fonte: Elaboração própria.

\subsection{Enquadramento do estudo}

Conforme ilustrado da Figura 3, vinte e nove artigos se enquadraram como teórico-empíricos e 16 como teóricos. 
Figura 3 - Distribuição dos artigos de acordo com o enquadramento do estudo

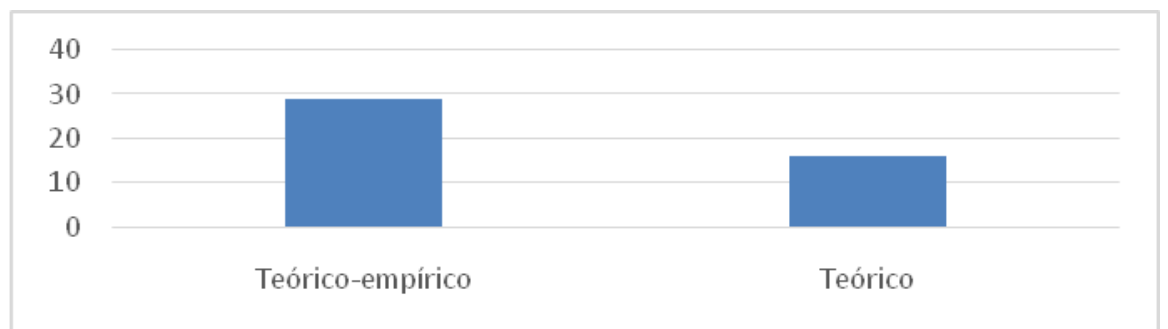

Fonte: Elaboração própria.

Adotou-se a definição de que a pesquisa teórico-empírica apresenta dados coletados, analisados e correlacionados com as teorias revisadas, e a pesquisa teórica se limita à articulação, proposição e contraposição de considerações teóricas, não apresentando dados empíricos (MACHADODA-SILVA; CUNHA; AMBONI, 1990). Por tal classificação, 64,44\% dos artigos analisados se enquadraram como teórico-empíricos e 35,56\% como teóricos.

É relevante constatar que a maior parte dos artigos publicados envolvem pesquisa empírica, indicando que os estudos têm sido voltados para produção de conhecimento com levantamento de dados sobre a realidade da IC no contexto nacional. Com o objetivo de entender melhor qual a natureza dessa produção, serão analisados nas próximas subseções apenas os 29 artigos classificados como teórico-empíricos.

\subsection{Natureza da pesquisa}

Dos 29 artigos teórico-empíricos analisados, quinze utilizaram a abordagem qualitativa $(51,72 \%)$, nove empregaram multi métodos $(31,03 \%)$, conjugando dados quantitativos e qualitativos, e 5 usaram a quantitativa $(17,24 \%)$, como mostra a Figura 4.

Figura 4 - Distribuição dos artigos de acordo com a natureza da pesquisa 


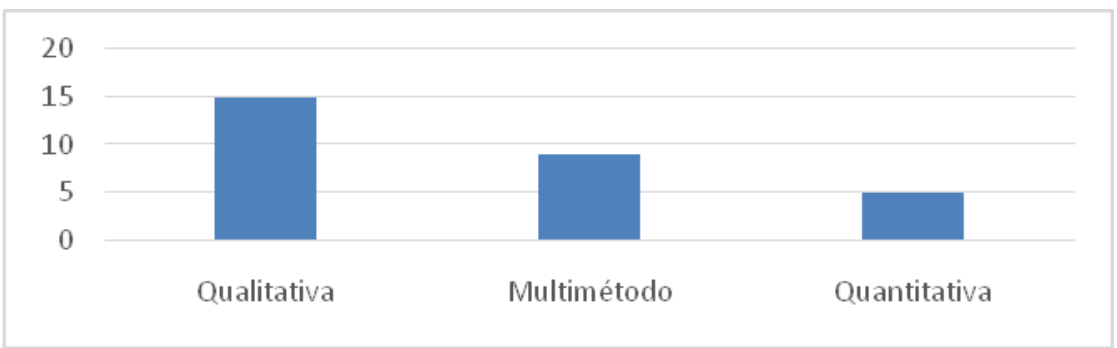

Fonte: Elaboração própria.

Destacam-se pesquisas com abordagem qualitativa se mostraram predominantes, seja em método único, seja conjugado. Ao mesclar as abordagens qualitativas e quantitativas, pesquisas multi métodos propiciam uma triangulação metodológica, a qual possibilita uma compreensão melhor do fenômeno (ALMEIDA et al., 2018).

\subsection{Instrumentos de coleta de dados}

A Figura 6 apresenta os instrumentos de coleta de dados utilizados nos 29 estudos teórico-empíricos, a saber: levantamento de documentos, com 17 utilizações, entrevista, realizada em12 artigos, questionário, em seis estudos, e grupo focal, em apenas um.

Figura 6 - Distribuição dos artigos de acordo com o instrumento de coleta de dados

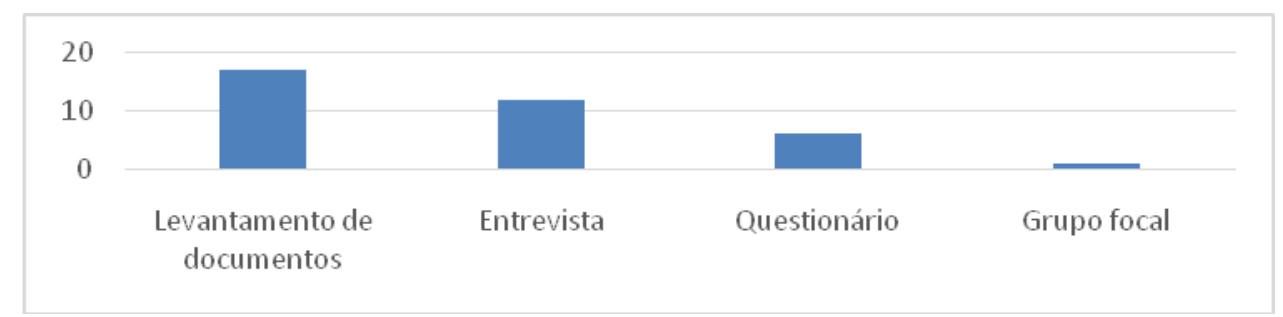

Fonte: Elaboração própria.

Sobre os quatro instrumentos de coleta de dados utilizados nos estudos teórico-empíricos, o mais empregado foi o levantamento documental $(58,62 \%)$, seguido de entrevista $(41,38 \%)$, de questionário $(20,69 \%)$ e de grupo focal $(3,45 \%)$. Outros instrumentos como observação e experimento sequer foram empregados.

\subsection{Técnicas de análise de dados}

Conforme sumarizado na Tabela 7, dos 29 artigos teóricos-empíricos analisados, oito não informaram sobre a técnica de análise de dados empregadas. Nos demais, foram adotadas a análise documental, empregada em sete artigos, a análise bibliométrica, utilizada em seis estudos, a análise estatística, também usada em seis, a análise de conteúdo, aplicada em cinco pesquisas, a análise de cluster, adotada em dois artigos e a análise multivariada de dados, em um estudo. 
Em síntese, 27,59\% dos estudos não informaram a técnica de análise de dados empregadas (o que parece não ser condizente com periódicos de primeira linha). Nos demais, foram utilizadas várias técnicas, sendo a preponderante a análise documental (24,14\%), prosseguida da análise bibliométrica e estatística (20,69\% cada).

Figura 7 - Distribuição dos artigos de acordo com o instrumento de coleta de dados

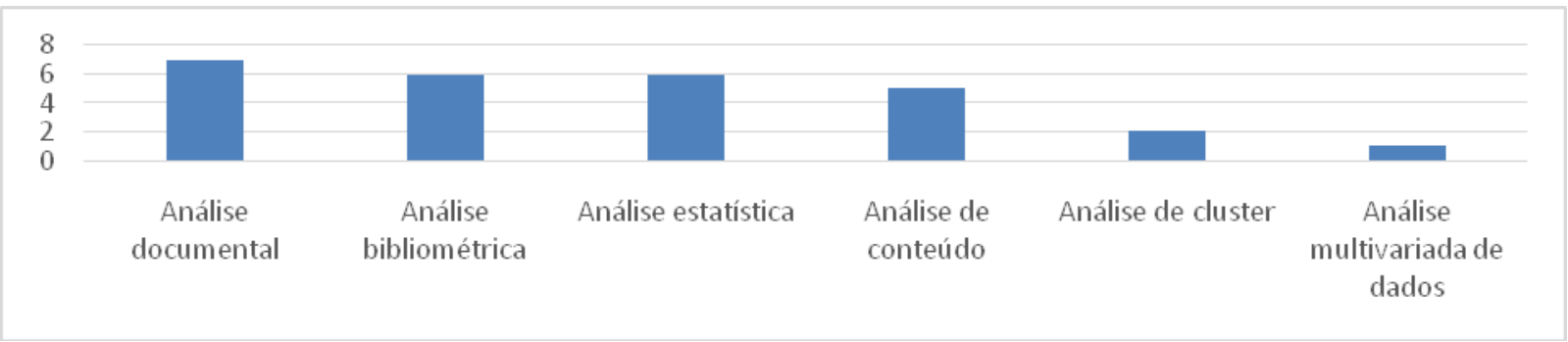

Fonte: Elaboração própria.

\subsection{Setor da economia}

Como se verifica na Figura 5, treze artigos teórico-empíricos não delimitaram o setor da economia, dez focalizaram o segundo setor, quatro, o primeiro, e dois estudaram empresas do primeiro e do segundo setores.

Figura 5 - Distribuição dos artigos de acordo com o setor da economia

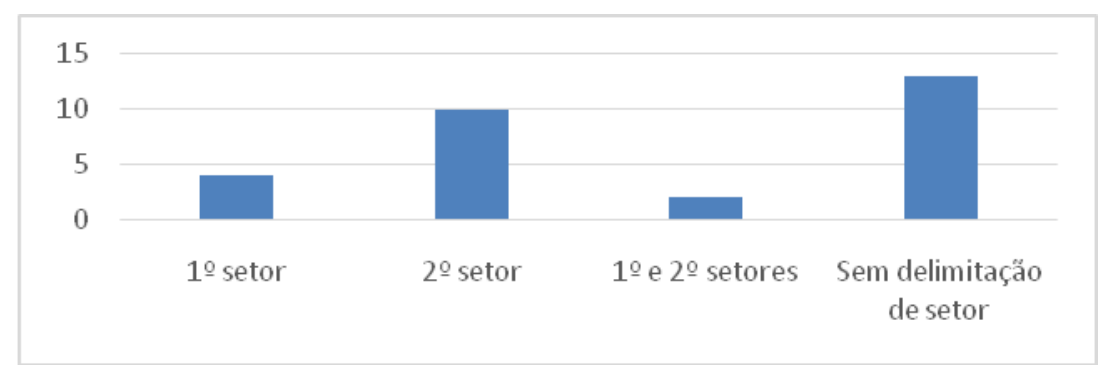

Fonte: Elaboração própria.

A definição dos setores da economia aqui adotada se baseia em Fernandes (1994), a saber: 1) primeiro setor: abarca as organizações públicas de interesse e/ou finalidade pública; 2) segundo setor: abrange as organizações privadas de interesse e/ou finalidade privada; e 3) terceiro setor: engloba as organizações privadas de interesse e/ou finalidade pública. Com base nessa classificação, 44,83\% dos artigos 
teórico-empíricos não apresentaram delimitação de setor da economia, $41,38 \%$ focaram no segundo setor e $20,69 \%$ se centraram no primeiro setor. Esses resultados indicam que dos 29 artigos teórico-empíricos analisados, apenas quatro se destinaram a tratar especificamente a IC em organizações públicas, reforçando a literatura de que essa temática ainda é predominantemente focada nas organizações privadas (ALMEIDA; MARICATO, 2015).

Também se observa que, de acordo com este levantamento, os artigos sobre IC não ficaram circunscritos a estudos mais genéricos sobre a sua aplicação. Como se pode ver de forma mais detalhada no Quadro 6, grande parte da produção ficou delimitada à análise dentro de um tipo específico de organização, principalmente no que tange à área de serviços.

\subsection{Ramo de atuação das organizações pesquisadas}

O Quadro 6 esquematiza o ramo de atuação das organizações pesquisadas nos estudos teóricos-empíricos. Como se percebe, onze não o delimitaram ou informaram;cinco estudaram organizações de diversos setores;3 investigaram instituições de ensino superior; dois, indústria; e dois, instituição financeira ou bancária. Os demais ramos apareceram apenas em um artigo: consultoria, empresa da área de energia, gestão pública, pesquisa, saúde, setor automotivo e tecnologia da informação.

Quadro 6 - Distribuição artigos de acordo como o ramo das organizações

\begin{tabular}{|l|c|}
\hline \multicolumn{1}{|c|}{ Assuntos } & Qtde \\
\hline Diversos setores & 5 \\
\hline Instituição de ensino superior & 3 \\
\hline Indústria & 2 \\
\hline Instituição financeira/bancária & 2 \\
\hline Consultoria & 1 \\
\hline Empresa da área de energia & 1 \\
\hline Gestão pública & 1 \\
\hline Pesquisa & 1 \\
\hline Saúde & 1 \\
\hline Setor automotivo & 1 \\
\hline Tecnologia da informação & 1 \\
\hline Não delimitado/informado & 11 \\
\hline
\end{tabular}

Fonte: Elaboração própria.

\section{Conclusão}

O presente trabalho cumpriu o seu objetivo de realizar uma revisão sistemática da literatura sobre IC, contribuindo para a produção acadêmica sobre a temática.

A revisão permitiu apresentar um panorama sobre a evolução dos estudos de IC publicados e, à guisa de conclusão, constatou que a média 
de publicações ao longo dos 22 anos de estudo sobre IC apontados no período (de 1999 a 2020) foi de dois artigos por ano. Esse baixo número configura uma escassez de investigação nacional sobre a temática em periódicos de primeira linha.

Além disso, não se apresentou regularidade das publicações sobre IC ao longo do tempo. No que tange a periódicos classificados com melhores estratos, a temática apresentou-se investigada apenas pela área da ciência da informação, de acordo com os critérios de busca adotados neste trabalho. Por tal razão, sugere-se, como agenda de pesquisa futura, investigar possíveis razões para a área da administração não priorizar a publicação de estudos sobre IC em periódicos melhor classificados. Indicase também pesquisar o panorama de publicações dessa área, bem como também da ciência da informação, em periódicos de estratos inferiores a $\mathrm{A} 1$, preferencialmente até o $\mathrm{B} 2$, para se manter um padrão razoável de qualidade.

Como limitações, esta pesquisa trabalhou apenas com artigos recuperados da base de periódicos da Capes, SciELO e Brapci, por entender serem os mais expressivos em termos de publicações nacionais. Propõe-se, no entanto, estender o estudo a outras bases de dados que também disponibilizem periódicos com alto fator de impacto.Publicações internacionais igualmente podem ser incluídas em estudos futuros.

Por fim, conclui-se que pesquisas relacionadas à IC ainda são predominantemente destinadas à esfera privada. Indica-se, como lacuna de pesquisa aqui identificada, a aplicação de estudos que investiguem a IC aplicada ao setor público, especialmente no que concerne às questões relacionadas à concorrência, vantagem competitiva e competitividade nessa esfera.

\section{Referências}

ALMEIDA, A. L.;MARICATO, J. M. Prospecção de cenários e monitoramento informacional como ferramentas de inteligência competitiva para o planejamento de políticas públicas no Estado de Goiás. Informação e Informação, v. 20, n. 3, p. 248273, 2015. Disponível em: https://brapci.inf.br/index.php/res/download/45168. Acesso em: 06 set. 2021.

ALMEIDA, W.A. C. et al. Compras estratégicas no setor público: uma revisão sistemática da produção nacional. Gestão.Org, v. 16, n. 2, p. 117-131, 2018. Disponível em: https://periodicos.ufpe.br/revistas/gestaoorg/article/view/237545/31016. Acesso em: 06 set. 2021.

BATTAGLIA, M.G.B. A Inteligência Competitiva modelando o sistema de informação de clientes - Finep. Ciência da Informação, v. 29, n. 2, p. 200214, 1999. 
Disponível em: https://www.scielo.br/j/ci/a/yM6gpSWbVYwtnjRD8Z4VwBJ/?lang=pt. Acesso em: 06 set. 2021.

BARRANCOS, J. E.;DUARTE, W. N. Inteligência competitiva e as práticas de gestão do conhecimento no contexto da administração e da ciência da informação: revelações da produção científica. Encontros Bibli: Revista Eletrônica de Biblioteconomia e Ciência da Informação, v. 18, n. 38, p. 107-126, 2013. Disponível em:

https://periodicos.ufsc.br/index.php/eb/article/view/1518-

2924.2013v18n38p107/25959 . Acesso em: 06 set. 2021.

BESSON, B.;POSSIN, J.-C. Du renseignement à l'intelligence économique. Paris: Dunod, 1997. Disponível em:

https://www.entreprises.gouv.fr/files/files/directions services/information-strategiquesisse/rapport-martre.pdf. Acesso em: 06 set. 2021.

BOSE, R. Competitive intelligence process and tools for intelligence analysis. Industrial Management \& Data Systems, v. 108, n. 4, p. 510528, 2008. Disponível em:

https://www.researchgate.net/publication/220672640 Competitive intelligence proce ss and tools for intelligence analysis. Acesso em: 06 set. 2021.

CAPUANO, E. A. et al. Inteligência competitiva e suas conexões epistemológicas com a gestão da informação e do conhecimento. Ciência da Informação, v. 38, n. 2, p. 19-34, 2009. . Disponível em: https://www.scielo.br/j/ci/a/Zz45KyPX8XnQCVCrqwFPDqg/?lang=pt. Acesso em: 06 set. 2021.

CORRE IA, J. J. A. et al. Características da produção científica acerca do tema inteligência competitiva: uma análise bibliométrica. Ciência da Informação, v. 48, n. 3, p. 34-50, 2019. Disponível em: http://revista.ibict.br/ciinf/article/view/4538/4288. Acesso em: 06 set. 2021.

CRONIN, P.;RYAN, F.;COUGHLAN, M. Undertaking a literature review: a step-by-step approach. British Journal of Nursing, v. 17, n. 1, p. 38-43, 2008. Disponível em:

https://www.researchgate.net/publication/5454130 Undertaking a literature review A step-by-step approach. Acesso em: 06 set. 2021.

DE PELSMACKER, P. et al. Competitive intelligence practices of South African and Belgian exporters. Marketing Intelligence \& Planning, v. 23, n. 6, p. 606-620, 2005. Disponível em: https://www.researchgate.net/publication/241711918 Competitive intelligence practi ces of South African and Belgian exporters. Acesso em: 06 set. 2021.

DISHMAN, P. L. ;CALOF, J. L. Competitive intelligence: a multiphasic precedent to marketing strategy. European Journal of Marketing, v. 42, n. 
7/8, p. 766-785, 2008. Disponível em:

https://www.researchgate. net/publication/242344293 Competitive intelligence A m ultiphasic precedent to marketing strategy. Acesso em: 06 set. 2021.

FACHINELLI, A. C. et al. Inteligência estratégica: desenvolvimento de uma escala para compreensão do construto. REBRAE: Revista Brasileira de Estratégia, v. 6, n. 2, p. 179-191, 2013. Disponível em: https://periodicos.pucpr.br/index.php/REBRAE/article/view/13916/13346. Acesso em: 06 set. 2021.

FERNANDES, F. C. Inteligência e gestão estratégica. Revista Brasileira de Inteligência, Brasília, v. 7, p. 21-30, 2012. Disponível em: https://www.sagres.org.br/artigos/relacao sinergica.pdf. Acesso em: 06 set. 2021.

FERNANDES, R. C. Privado porém público: o terceiro setor na América Latina. Rio de Janeiro: Relume-Dumará, 1994.

GUEDES, I. A.; CÂNDIDO, G. A. Modernização administrativa no setor público: utilização de tecnologias de gestão e de informação para o gerenciamento do conhecimento. Gestão.Org., v. 6, n. 2, p. 158-173, 2008. Disponível em:

https://periodicos.ufpe.br/revistas/gestaoorg/article/view/21621/18314. Acesso em: 06 set. 2021.

HERMAN, M. Intelligence power in peace and war. Cambridge: Cambridge University Press, 1996.

KAHANER, L. Competitive intelligence: how to gather, analyse, and use information to move your business to the top. New York: Simon \& Schuter, 1996.

KENT, S. Strategic intelligence for american world policy. Rio de Janeiro: Biblioteca do Exército, 1949.

MARCIAL, E. C. Os desafios do profissional de inteligência: uma atividade em evolução. In: STAREC, C. (org.). Gestão da formação, inovação e inteligência competitiva: como transformar a informação em vantagem competitiva nas organizações. São Paulo: Saraiva, 2012. Cap. 8.

MARCIAL, E.C. Proposta inicial de uma teoria geral de inteligência competitiva. Ciência da Informação, v. 45, n. 3, p. 59-75, 2016. Disponível em: http://revista.ibict.br/ciinf/article/view/4048/3566. Acesso em: 06 set. 2021.

MARCIAL, E.C.;SUAIDEN, E. J. A estrutura científica da inteligência competitiva. Transinformação, v. 28, n. 1, p. 97-106, 2016. Disponível em: https://www.scielo.br///tinf/a/vLMwkzRsktQQnmhYXxG3Htq/?lang=pt. Acesso em: 06 set. 2021. 
MACHADO-DA-SILVA, C.L.; CUNHA, V. C.;AMBONI, N. Organizações: o estado da arte da produção acadêmica no Brasil. [S.I: s.n.], 1990. p. 1128.

MENDES, A. ;MARCIAL, E. ;FERNANDES, F. Fundamentos da Inteligência Competitiva. Brasília: Thesaurus, 2010.

PELLISSIER, R. ;NENZHELELE, T. E. Towards a universal definition of competitive intelligence. South African Journal of Information Management, v. 15, n. 2, p. 559, 2013. Disponível em:

https://www.researchgate.net/publication/276199063 Towards a universal definitio $\mathrm{n}$ of competitive intelligence. Acesso em: 06 set. 2021.

PRADO, A. E.; CAMPOS, F. C. Análise bibliométrica 1990-2014:

inteligência competitiva. Perspectivas em Ciência da Informação, v. 23, n. 1, p. 71-88, 2018. Disponível em:

https://www.scielo.br/j/pci/a/3JCQbYpBMLfcM3ZGdRgmwcJ/?lang=pt. Acesso em: 06 set. 2021.

RIBEIRO, A. C. M. L. ; SANTOS, C. D. Isso não é uma pirâmide: revisando o modelo clássico de dado, informação, conhecimento e sabedoria. Ciência da Informação, v. 49, n. 2, p. 67-87, 2020. Disponível em:

http://revista.ibict.br/ciinf/article/view/5066/5247. Acesso em: 06 set. 2021.

RIOS, F. L. C. et al. Inteligência competitiva, empresarial, estratégica ou de negócios? Um olhar a partir da administração de empresas. FACEF Pesquisa, v. 14,p. 28-44, 2011. Disponível em:

https://periodicos.unifacef.com.br/index.php/facefpesquisa/article/view/278/269.

Acesso em: 06 set. 2021.

SILVA, A. M.;ANDRADE, E. P. Inteligência competitiva e gestão por competência como horizonte de ação para os Núcleos de Inovação Tecnológica em instituições públicas de ciência e tecnologia. In: ENCONTRO DA ANPAD. Anais [...] v. 37, 2013. Disponível em: http://www.anpad.org.br/diversos/down zips/68/2013 EnANPAD GCT1755.pdf. Acesso em: 06 set. 2021.

SILVA, F. A.;GONÇALVES, C. A. O processo de formulação e implementação de planejamento estratégico em instituições do setor público. Revista de Administração da UFSM, v. 4, n. 3, p. 458-476, 2011. Disponível em: https://www.redalyc.org/pdf/2734/273421614010.pdf. Acesso em: 06 set. 2021.

SØILEN, K. S. A place for intelligence studies as a scientific discipline. Journal of Intelligence Studies in Business, v. 5, n. 3, p. 35-46, 2015. 
Disponível em: https://www.semanticscholar.org/paper/A-place-for-intelligencestudies-as-a-scientific-S\%C3\%B8ilen/cef2c97d4f2bbf2230f0a78377662e389b2a0fbc. Acesso em: 06 set. 2021.

TARAPANOFF, K. Inteligência, informação e conhecimento. Brasília: IBICT, Unesco, 20016.

VALENTIM, M. L. et al. O processo de inteligência competitiva em organizações. DataGramaZero, v. 4, n. 3, 2003. Disponível em: https://brapci.inf.br/index.php/res/download/44760. Acesso em: 06 set. 2021.

WAGNER, R. B. Can competitive intelligence be effectively applied to public-sector organizations? In: FLEISHER, C.; BLENKHORN, D.L. (Ed.). Controversies in competitive intelligence: the enduring issues. Westport, CT: Praeger, 2003. p. 70-82.

WIGGINS, R.R.;RUEFLI, T. W. Sustained competitive advantage: temporal dynamics and the incidence and persistence of superior economic performance. Organization Science, v. 13, n. 1, p. 81-105, 2002. Disponível em: https://www.researchgate.net/publication/262233408 Sustained Competitive Advan tage Temporal Dynamics and the Incidence and Persistence of Superior Econ omic Performance. Acesso em: 06 set. 2021.

\section{Apêndice}

Tabela A -Artigos selecionados

\begin{tabular}{|c|c|c|c|c|}
\hline $\mathbf{N}$ & Autor(es) & Título & Periódico & $\begin{array}{c}\text { Ano de } \\
\text { publicação }\end{array}$ \\
\hline 1 & $\begin{array}{l}\text { ALCARÁ, A. R. } \\
\text { et al. }\end{array}$ & $\begin{array}{l}\text { As redes sociais como instrumento } \\
\text { estratégico para a inteligência competitiva }\end{array}$ & Transinformação & 2006 \\
\hline 2 & $\begin{array}{l}\text { ALMEIDA, A. L.; } \\
\text { MARICATO, J. } \\
\text { M. }\end{array}$ & $\begin{array}{l}\text { Prospecção de cenários e monitoramento } \\
\text { informacional como ferramentas de } \\
\text { inteligência competitiva para } 0 . .\end{array}$ & $\begin{array}{l}\text { Informação \& } \\
\text { Informação }\end{array}$ & 2015 \\
\hline 3 & $\begin{array}{l}\text { AMARAL, R. M. } \\
\text { A. et al. }\end{array}$ & $\begin{array}{l}\text { Panorama da inteligência competitiva no } \\
\text { Brasil: os pesquisadores e a produção } \\
\text { científica... }\end{array}$ & $\begin{array}{l}\text { Perspectivas em } \\
\text { Ciência da } \\
\text { Informação }\end{array}$ & 2016 \\
\hline 4 & $\begin{array}{l}\text { ARAÚJO } \\
\text { JÚNIOR, R. H.; } \\
\text { PERUCCHI, V.; } \\
\text { LOPES, P. R. D. }\end{array}$ & $\begin{array}{l}\text { Análise bibliométrica dos temas } \\
\text { inteligência competitiva, gestão do } \\
\text { conhecimento e conhecimento } \\
\text { organizacional, no repositório... }\end{array}$ & $\begin{array}{l}\text { Perspectivas em } \\
\text { Ciência da } \\
\text { Informação }\end{array}$ & 2013 \\
\hline 5 & $\begin{array}{l}\text { BARBOSA, R. } \\
\text { R. }\end{array}$ & $\begin{array}{l}\text { Uso de fontes de informação para a } \\
\text { inteligência competitiva: um estudo da } \\
\text { influência do porte das empresas sobre o... }\end{array}$ & Encontros Bibli & 2006 \\
\hline 6 & $\begin{array}{l}\text { BARRANCOS, } \\
\text { J. E.; DUARTE, } \\
\text { E. N. }\end{array}$ & $\begin{array}{l}\text { Inteligência competitiva e as práticas de } \\
\text { gestão do conhecimento no contexto da } \\
\text { administração e da ciência da... }\end{array}$ & Encontros Bibli & 2013 \\
\hline 7 & BORGES, M. E. & Inteligência competitiva: o relato de dois & Informação \& & 2008 \\
\hline
\end{tabular}




\begin{tabular}{|c|c|c|c|c|}
\hline & $\begin{array}{l}\text { N.; RIBEIRO, C. } \\
\text { E.; CAIXETA, } \\
\text { M. L. }\end{array}$ & casos brasileiros. & Informação & \\
\hline 8 & $\begin{array}{l}\text { BORGES, M. E. } \\
\text { N.; SANTOS, E. } \\
\text { L. }\end{array}$ & $\begin{array}{l}\text { O profissional da informação em atividades } \\
\text { de inteligência competitiva }\end{array}$ & $\begin{array}{l}\text { Informação \& } \\
\text { Informação }\end{array}$ & 2009 \\
\hline 9 & $\begin{array}{l}\text { CANONGIA, C. } \\
\text { et al. }\end{array}$ & $\begin{array}{l}\text { Mapeamento de inteligência competitiva } \\
\text { (IC) e de gestão do conhecimento (GC) no } \\
\text { setor saúde }\end{array}$ & Encontros Bibli & 2004 \\
\hline 10 & $\begin{array}{l}\text { CARVALHO, M. } \\
\text { E. et al. }\end{array}$ & $\begin{array}{l}\text { As contribuições da inteligência } \\
\text { competitiva para a estratégia no contexto } \\
\text { de uma instituição bancária }\end{array}$ & $\begin{array}{l}\text { Informação \& } \\
\text { Informação }\end{array}$ & 2018 \\
\hline 11 & $\begin{array}{l}\text { CORSATTO, C. } \\
\text { A.; } \\
\text { HOFFMANN, } \\
\text { W. A. M. }\end{array}$ & $\begin{array}{l}\text { Gestão do conhecimento e inteligência } \\
\text { competitiva: delineamento de estratégias } \\
\text { de competitividade e inovação para } \\
\text { pequenas empresas }\end{array}$ & Encontros Bibli & 2013 \\
\hline 12 & $\begin{array}{l}\text { COSTA, M. D.; } \\
\text { SILVA, I. A. }\end{array}$ & $\begin{array}{l}\text { Inteligência competitiva: uma abordagem } \\
\text { sobre a coleta de informações publicadas }\end{array}$ & $\begin{array}{l}\text { Informação \& } \\
\text { Sociedade }\end{array}$ & 1999 \\
\hline 13 & $\begin{array}{l}\text { FALSARELLA, } \\
\text { O. M.; } \\
\text { JANNUZZI, C. } \\
\text { S. C. }\end{array}$ & $\begin{array}{l}\text { Inteligência organizacional e competitiva e } \\
\text { big data: uma visão sistêmica para a } \\
\text { gestão sustentável das organizações }\end{array}$ & $\begin{array}{l}\text { Perspectivas em } \\
\text { Ciência da } \\
\text { Informação }\end{array}$ & 2020 \\
\hline 14 & GARCIA, L. G. & $\begin{array}{l}\text { Ensino de inteligência competitiva no apoio } \\
\text { à busca do sucesso profissional de } \\
\text { graduandos em Biblioteconomia e... }\end{array}$ & $\begin{array}{l}\text { Perspectivas em } \\
\text { Ciência da } \\
\text { Informação }\end{array}$ & 2020 \\
\hline 15 & GARCIA, L. G. & $\begin{array}{l}\text { Roteiros de desenvolvimento de unidades } \\
\text { de inteligência competitiva sob a ótica dos } \\
\text { modelos de referência }\end{array}$ & Encontros Bibli & 2013 \\
\hline 16 & JAMIL, G. L. & $\begin{array}{l}\text { Aspectos do ambiente gerencial e seus } \\
\text { impactos no uso dos sistemas de } \\
\text { inteligência competitiva para processos... }\end{array}$ & $\begin{array}{l}\text { Perspectivas em } \\
\text { Ciência da } \\
\text { Informação }\end{array}$ & 2001 \\
\hline 17 & $\begin{array}{l}\text { HOFFMANN, } \\
\text { W. A. M.; } \\
\text { GREGOLIN, J. } \\
\text { A. R.; OPRIME, } \\
\text { P. C. }\end{array}$ & $\begin{array}{l}\text { A contribuição da inteligência competitiva } \\
\text { para o desenvolvimento de arranjos } \\
\text { produtivos locais: caso Jaú-SP }\end{array}$ & Encontros Bibli & 2004 \\
\hline 18 & $\begin{array}{l}\text { LUCAS, A.; } \\
\text { CAFÉ, L. M. A.; } \\
\text { VIEIRA, A. F. G. }\end{array}$ & $\begin{array}{l}\text { Inteligência de negócios e inteligência } \\
\text { competitiva na ciência da informação } \\
\text { brasileira: contribuições para uma... }\end{array}$ & $\begin{array}{l}\text { Perspectivas em } \\
\text { Ciência da } \\
\text { Informação }\end{array}$ & 2016 \\
\hline 19 & $\begin{array}{l}\text { MARCIAL, E. } \\
\text { C.; SUAIDEN, } \\
\text { E. J. }\end{array}$ & $\begin{array}{l}\text { A estrutura científica da inteligência } \\
\text { competitiva }\end{array}$ & Transinformação & 2016 \\
\hline 20 & MARCO, S. A. & $\begin{array}{l}\text { Inteligência competitiva: definições e } \\
\text { contextualização }\end{array}$ & Transinformação & 1999 \\
\hline 21 & $\begin{array}{l}\text { MARQUES, L. } \\
\text { K. S.; VIDIGAL, } \\
\text { F. }\end{array}$ & $\begin{array}{l}\text { Prosumers e redes sociais como fontes de } \\
\text { informação mercadológica: uma análise } \\
\text { sob a perspectiva... }\end{array}$ & Transinformação & 2018 \\
\hline 22 & $\begin{array}{l}\text { MIQUELINO, F. } \\
\text { L. C.; SANTOS, } \\
\text { R. N. M. }\end{array}$ & $\begin{array}{l}\text { Conformação de plano de suprimento dos } \\
\text { serviços em telecom integrado ao plano } \\
\text { informacional }\end{array}$ & Transinformação & 2001 \\
\hline 23 & $\begin{array}{l}\text { MIQUELINO, F. } \\
\text { L. C.; SANTOS, } \\
\text { R. N. M.; } \\
\text { PADOVANI, R. } \\
\text { C. }\end{array}$ & $\begin{array}{l}\text { A inteligência competitiva aplicada à } \\
\text { comunicação e à arquitetura da marca de } \\
\text { uma organização }\end{array}$ & Encontros Bibli & 2004 \\
\hline 24 & $\begin{array}{l}\text { MILANI } \\
\text { JÚNIOR, A. }\end{array}$ & $\begin{array}{l}\text { Base conceitual para implantação de um } \\
\text { sistema de inteligência competitiva na } \\
\text { Braspetro }\end{array}$ & Transinformação & 1999 \\
\hline
\end{tabular}




\begin{tabular}{|c|c|c|c|c|}
\hline 25 & $\begin{array}{l}\text { NADAES, A. D.; } \\
\text { BORGES, M. E. } \\
\text { N. }\end{array}$ & $\begin{array}{l}\text { Inteligência competitiva e internet: um } \\
\text { processo otimizado por agentes } \\
\text { inteligentes... }\end{array}$ & Transinformação & 2005 \\
\hline 26 & OLIVEIRA, P. H. & $\begin{array}{l}\text { Modelo de avaliação de risco do capital } \\
\text { humano em atividades de inteligência } \\
\text { competitiva (MARCHAIC): uma proposta... }\end{array}$ & Encontros Bibli & 2009 \\
\hline 27 & $\begin{array}{l}\text { OLIVEIRA, P. } \\
\text { H.; SADE, W. }\end{array}$ & $\begin{array}{l}\text { Inteligência competitiva no contexto das } \\
\text { empresas mineiras de artefatos de estanho }\end{array}$ & $\begin{array}{l}\text { Perspectivas em } \\
\text { Ciência da } \\
\text { Informação }\end{array}$ & 2016 \\
\hline 28 & $\begin{array}{l}\text { OTTONICAR, S. } \\
\text { L. C. et al. }\end{array}$ & $\begin{array}{l}\text { Competência midiática no processo de } \\
\text { inteligência competitiva voltada ao uso das } \\
\text { mídias sociais: modelo de inter-relação... }\end{array}$ & $\begin{array}{l}\text { Perspectivas em } \\
\text { Ciência da } \\
\text { Informação }\end{array}$ & 2021 \\
\hline 29 & $\begin{array}{l}\text { PERUCCHI, V.; } \\
\text { ARAÚJO } \\
\text { JÚNIOR, R. H. }\end{array}$ & $\begin{array}{l}\text { Produção cient ífica sobre inteligência } \\
\text { competitiva da Faculdade de Ciência da } \\
\text { Informação da Universidade de Brasília }\end{array}$ & $\begin{array}{l}\text { Perspectivas em } \\
\text { Ciência da } \\
\text { Informação }\end{array}$ & 2012 \\
\hline 30 & $\begin{array}{l}\text { PINTRO, S.; } \\
\text { VIANNA, W. B.; } \\
\text { VARVAKIS, G. }\end{array}$ & $\begin{array}{l}\text { Inteligência competitiva e ciência da } \\
\text { informação: conexões epistemológicas } \\
\text { para tomada de decisão nas organizações }\end{array}$ & Em Questão & 2016 \\
\hline 31 & $\begin{array}{l}\text { PRADO, A. E.; } \\
\text { CAMPOS, F. C. }\end{array}$ & $\begin{array}{l}\text { Análise bibliométrica 1990-2014: } \\
\text { inteligência competitiva }\end{array}$ & $\begin{array}{l}\text { Perspectivas em } \\
\text { Ciência da } \\
\text { Informação }\end{array}$ & 2018 \\
\hline 32 & $\begin{array}{l}\text { SILVA, C. B. et } \\
\text { al. }\end{array}$ & $\begin{array}{l}\text { Proposição e validação de um modelo de } \\
\text { inteligência competitiva específico para } \\
\text { Instituições de Ensino Superior (IES)... }\end{array}$ & $\begin{array}{l}\text { Perspectivas em } \\
\text { Ciência da } \\
\text { Informação }\end{array}$ & 2018 \\
\hline 33 & $\begin{array}{l}\text { SILVA, F. A. C.; } \\
\text { ESPÍNDOLA, M. } \\
\text { J. V. }\end{array}$ & $\begin{array}{l}\text { Gestão do conhecimento e inteligência } \\
\text { competitiva: desafios para as organizações } \\
\text { produtivas }\end{array}$ & $\begin{array}{l}\text { Informação \& } \\
\text { Sociedade }\end{array}$ & 2006 \\
\hline 34 & $\begin{array}{l}\text { SILVA, P. N.; } \\
\text { MUYLDER, C. } \\
\text { F. }\end{array}$ & $\begin{array}{l}\text { Inteligência competitiva e cooperação na } \\
\text { percepção dos atores do arranjo produtivo } \\
\text { local de software da Região... }\end{array}$ & $\begin{array}{l}\text { Perspectivas em } \\
\text { Ciência da } \\
\text { Informação }\end{array}$ & 2015 \\
\hline 35 & $\begin{array}{l}\text { SILVA, T.; } \\
\text { MUDRIK, J.; } \\
\text { VIDIGAL, F. }\end{array}$ & $\begin{array}{l}\text { A inter-relação entre o processo de } \\
\text { inteligência competitiva e a gestão da } \\
\text { inovação: proposição de um modelo... }\end{array}$ & $\begin{array}{l}\text { Informação \& } \\
\text { Informação }\end{array}$ & 2018 \\
\hline 36 & $\begin{array}{l}\text { TARAPANOFF, } \\
\text { K. }\end{array}$ & $\begin{array}{l}\text { Inteligência social e inteligência } \\
\text { competitiva }\end{array}$ & Encontros Bibli & 2004 \\
\hline 37 & $\begin{array}{l}\text { TEIXEIRA, R. } \\
\text { C.; SOUZA, C. }\end{array}$ & $\begin{array}{l}\text { Evolução da inteligência competitiva com } \\
\text { base em estudo métrico de sua literatura }\end{array}$ & $\begin{array}{l}\text { Perspectivas em } \\
\text { Ciência da } \\
\text { Informação }\end{array}$ & 2017 \\
\hline 38 & $\begin{array}{l}\text { TEIXEIRA, R. } \\
\text { C.; SOUZA, R. } \\
\text { R. }\end{array}$ & $\begin{array}{l}\text { O uso das informações contidas em } \\
\text { documentos de patentes nas práticas de } \\
\text { Inteligência competitiva: apresentação de... }\end{array}$ & $\begin{array}{l}\text { Perspectivas em } \\
\text { Ciência da } \\
\text { Informação }\end{array}$ & 2013 \\
\hline 39 & $\begin{array}{l}\text { VALENTIM, M. } \\
\text { L. P.; } \\
\text { GELINSKI, J. V. } \\
\text { V. }\end{array}$ & $\begin{array}{l}\text { Gestão do conhecimento como parte do } \\
\text { processo de inteligência competitiva } \\
\text { organizacional }\end{array}$ & $\begin{array}{l}\text { Informação \& } \\
\text { Sociedade }\end{array}$ & 2005 \\
\hline 40 & $\begin{array}{l}\text { VALENTIM, M. } \\
\text { L. P.; MOLINA, } \\
\text { L. G. }\end{array}$ & $\begin{array}{l}\text { Prospeç̧ão e monitoramento } \\
\text { informacional no processo de inteligência } \\
\text { competitiva }\end{array}$ & Encontros Bibli & 2004 \\
\hline 41 & $\begin{array}{l}\text { VALENTIM, M. } \\
\text { L. P.; SOUZA, J. } \\
\text { S. F. }\end{array}$ & $\begin{array}{l}\text { Fluxos de informação que subsidiam o } \\
\text { processo de inteligência competitiva }\end{array}$ & Encontros Bibli & 2013 \\
\hline 42 & $\begin{array}{l}\text { VALENTIM, M. } \\
\text { L. P. et al. }\end{array}$ & $\begin{array}{l}\text { Pesquisa em inteligência competitiva } \\
\text { organizacional: utilizando a análise de } \\
\text { conteúdo... - Partes I e II }\end{array}$ & Transinformação & 2005 \\
\hline 43 & VIDIGAL, F. & $\begin{array}{l}\text { Competitive intelligence: functional } \\
\text { practices, goals and infrastructure of } \\
\text { companies in Brazil }\end{array}$ & Transinformação & 2013 \\
\hline
\end{tabular}




\begin{tabular}{|c|c|c|c|c|}
\hline 44 & $\begin{array}{l}\text { VIDIGAL, F.; } \\
\text { BORGES, E. N. }\end{array}$ & $\begin{array}{l}\text { Inteligência competitiva: metodologias } \\
\text { aplicadas em empresas brasileiras }\end{array}$ & $\begin{array}{l}\text { Informação \& } \\
\text { Informação }\end{array}$ & 2012 \\
\hline 45 & $\begin{array}{l}\text { VIDIGAL, F.; } \\
\text { GONÇALVES, } \\
\text { C. A.; SILVA, J. } \\
\text { R. }\end{array}$ & $\begin{array}{l}\text { Inteligência competitiva e capacidade de } \\
\text { inovação: uma análise de uma indústria de } \\
\text { classe mundial no setor automotivo de } \\
\text { veículos pesados }\end{array}$ & $\begin{array}{l}\text { Perspectivas em } \\
\text { Ciência da } \\
\text { Informação }\end{array}$ & 2018 \\
\hline
\end{tabular}

Fonte: Elaboração própria. 